\title{
Use of the Ophtec Artificial Iris Model C1 in Patients with Aniridia|Aphakia
}

\section{Aniridie-|Aphakieversorgung mittels Ophtec Artificial Iris Modell C1}

\author{
Authors \\ Juliane Jakob-Girbig ${ }^{\mathbb{D}}$, Susanne Salewsky, Daniel Meller \\ Affiliation \\ Augenklinik, Universitätsklinikum Jena, Deutschland \\ Key words \\ aniridia, aphakia, prosthetic iris implants, perforating \\ keratoplasty \\ Schlüsselwörter \\ Aniridie, Aphakie, Irisprothetik, perforierende Keratoplastik \\ $\begin{array}{ll}\text { received } & 29.1 .2021 \\ \text { accepted } & 1.3 .2021\end{array}$ \\ Bibliography \\ Klin Monatsbl Augenheilkd 2021; 238: 803-807 \\ DOI 10.1055/a-1475-1049 \\ ISSN $\quad 0023-2165$ \\ (C) 2021. Thieme. All rights reserved. \\ Georg Thieme Verlag KG, Rüdigerstraße 14, \\ 70469 Stuttgart, Germany \\ Correspondence \\ Dr. Juliane Jakob-Girbig \\ Augenklinik, Universitätsklinikum Jena \\ Am Klinikum 1, 07747 Jena, Deutschland \\ Phone: +49(0)36419329701, Fax: + 49(0)36419329702 \\ j.jakob@schoenburg.de
}

\begin{abstract}
In the present cases, the use of the Ophtec Arificial Iris model C1 is described in patients with traumatic or postoperative aniridia/aphakia. In one of the patients, it was combined with perforating keratoplasty because of corneal scarring. In both of the presented cases, improvement in visual acuity and a satisfactory aesthetic result without any serious complications can be shown. However, the short follow-up time must be emphasised.
\end{abstract}

\section{ZUSAMMENFASSUNG}

In den hier vorgestellten Kasuistiken wird die Versorgung mittels Ophtec Artificial Iris Modell C1 bei traumatischer bzw. postoperativer Aniride/Aphakie beschrieben. In einem Fall wird bei visuslimitierender Hornhautvernarbung zusätzlich die Kombination mit einer perforierenden Keratoplastik angewendet. Im Ergebnis zeigt sich in beiden Fällen ein Zugewinn von Visus und kosmetischer Zufriedenheit ohne schwerwiegende Komplikationen. Einschränkend muss aber auf den aktuell noch kurzen Nachbeobachtungszeitraum hingewiesen werden.

\section{Introduction}

Partial or complete loss of the iris can be due to ocular trauma, surgical procedures, inflammatory processes or congenital malformations [1]. Affected patients suffer especially from symptoms such as impaired vision and glare sensitivity and are troubled by the cosmetic impact of the iris defect [2].

There are now various ways of treating the iris defect surgically. These include artificial prosthetic iris systems. One of these systems is the Artificial Iris from the Ophtec company (relabelled, originally Reper). This is a foldable prosthetic iris $0.2 \mathrm{~mm}$ thick made of hydrophobic acrylic material. There are different models. In essence, model number 1 comes with and model number 0 without an optical effect and a further distinction is made between the type of fixation ( $\mathrm{C}$ : fixed to the sulcus, F: fixed to the capsular bag). Accordingly, the $\mathrm{C} 1$ model used here is sulcus-fixed and covers a dioptre range from 0.0 to $40.0 \mathrm{dpt}$ with a total diameter of $13.5 \mathrm{~mm}$ and a lens diameter of $3.5 \mathrm{~mm}$. All prosthetic irises are available in 120 different colour pattern designs so that a very individual choice to match the other eye can be made using a colour fan.

\section{Case 1}

\section{History and findings}

An 81-year-old patient attended our clinic because of spontaneous dislocation of the posterior chamber lens implanted 7 years previously and of the capsular bag into the vitreous space of the left eye. Pars plana vitrectomy was performed to retrieve the IOL 
and capsular bag. During this, iridodialysis occurred from 6:00 o'clock through 9:00 o'clock to 1:00 o'clock. The iris was reattached to the sclera with 10/0 Prolene. Following discharge from hospital and further office-based conservative management, vision of $0.5 \operatorname{logMAR}$ was found in the left eye with aphakia correction of $+12.0 \mathrm{dpt} 6$ months after operation. The anterior segment was uninflamed with aphakia, a clear cornea, corneoscleral sutures in the upper part, deep anterior chamber, avulsion of the base of the iris from 7:00 o'clock through 8:00 o'clock to 9:30 o'clock and a large iris defect from 9:30 o'clock through 11:00 o'clock to 12:00 o'clock ( $\triangleright$ Fig. 1) with intraocular pressure of $9 \mathrm{mmHg}$ and circularly attached retina. Because of the pronounced glare sensitivity and aphakia, surgical management of the aphakia and aniridia was planned.

\section{Operation and course}

One year after the complicated primary treatment of the left eye, surgical reconstruction was performed using the Ophtec Artificial Iris Model C1 (scleral fixation) shade no. 1048. The refractive strength of the IOL of $+22 \mathrm{dpt}$ was calculated via IOL-Master 700 (Zeiss) using the SRK-T/II formula with an A constant of 119.4.

The conjunctiva of the left eye was opened at 4:00 o'clock, 8:00 o'clock and 12:00 o'clock. The ciliary sulcus was marked by diaphanoscopy at 4:00 o'clock, 8:00 o'clock and 12:00 o'clock. Double-armed Prolene sutures were tied to the three loops of the IOL haptic. Guide cannulas were introduced into the sclera from without at 4:00 o'clock, 8:00 o'clock and 12:00 o'clock according to the previous marking and a three-stage corneal tunnel $4.5 \mathrm{~mm}$ wide was then opened and the Artificial Iris was brought out at 4:00 o'clock, 8:00 o'clock and 12:00 o'clock using the cannulas as a guide. The aniridia IOL was then fixed using a Szurman Z suture [3]. With the IOL correctly in place and the IOP restored the conjunctiva was closed with $8 / 0$ Vicryl and the sclerotomy with 7/0 Vicryl at 6:00 o'clock.

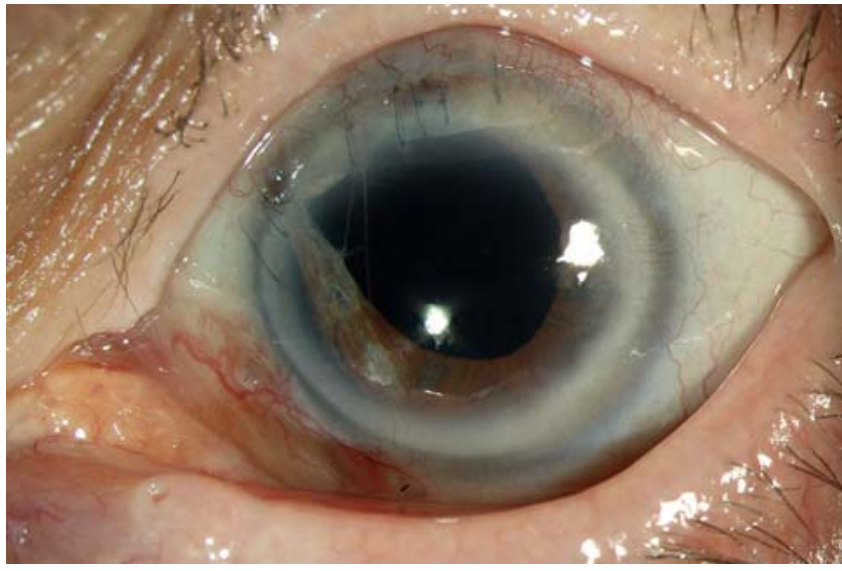

Fig. 1 Anterior segment of left eye, preoperative.

The patient was readmitted in the interim for corneal care because of marked punctate keratitis and resuture of the cornea because of suture avulsion at 8:00 o'clock. 6 months postoperatively, vision in the left eye was $0.6 \operatorname{logMAR}$ with subjective refraction of sph $+1.5 \mathrm{cyl}-3.5 \mathrm{~A} 110^{\circ}$. The anterior segment appeared uninflamed with the IOL well in place ( $\bullet$ Fig. 2 a). The anterior segment OCT confirmed the position of the IOL and the lens was readily distinguished from the prosthetic iris ( $\bullet$ Fig. $\mathbf{2}$ b). The patient was very happy with the cosmetic result compared with the

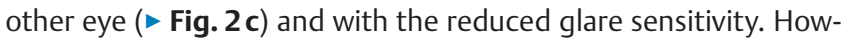
ever, there was mild epithelial oedema with an increase in corneal thickness ( $\bullet$ Fig. $\mathbf{2}$ d) and a reduction in the endothelial cell count to 386 cells $/ \mathrm{mm}^{2}$ indicating incipient corneal endothelial decompensation while the endothelial cell count was normal in the other eye ( 1219 cells $/ \mathrm{mm}^{2}$ ). In the absence of subjective complaints, we refrained from surgical measures in the form of DMEK and prescribed Omni-Sorb eye drops.
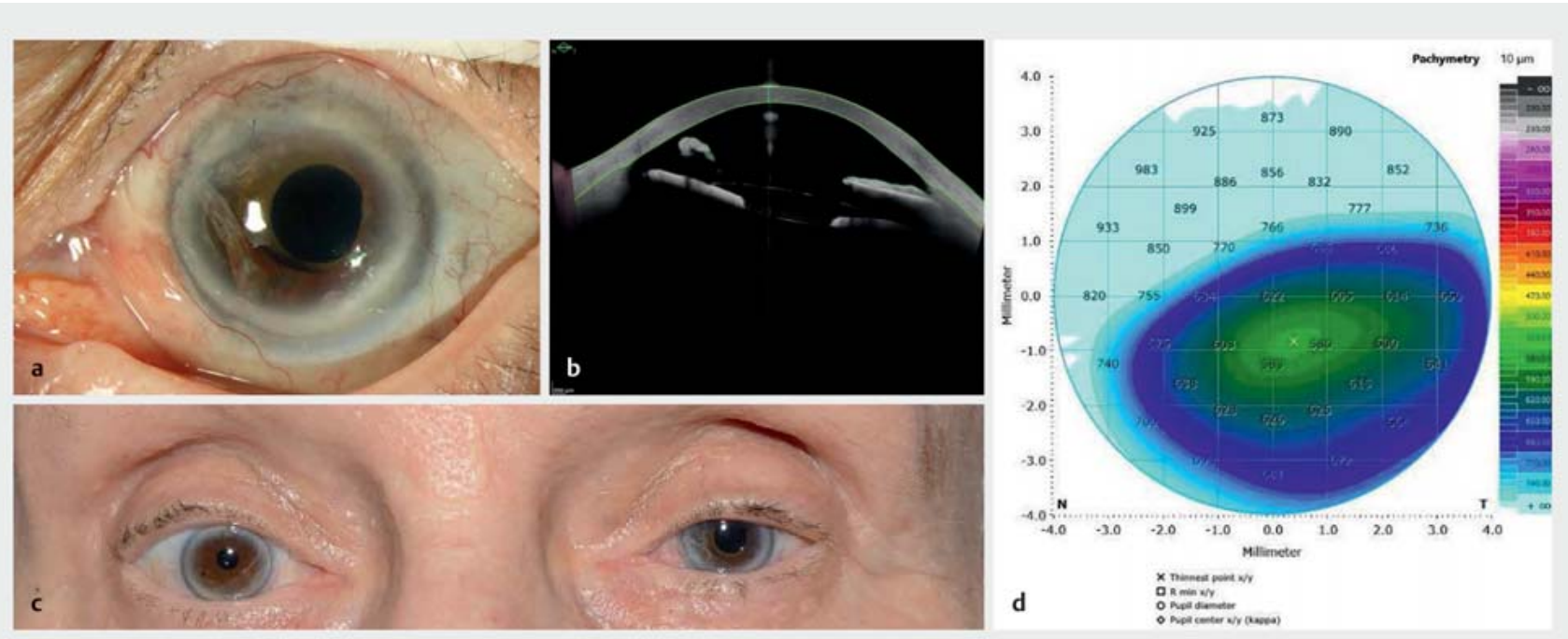

- Fig. 2 From top left to bottom right: a Anterior segment on left 6 months postoperatively. b Anterior segment OCT on left 6 months postoperatively. c Photograph 6 months postoperatively. $d$ Pachymetry on left 6 months postoperatively. 


\section{Case 2}

\section{History and findings}

A 21-year-old patient with a perforating injury of the cornea, sclera and iris, loss of the lens and nasal and temporal lid injury of the left eye due to an exploded glass bottle was treated in our clinic. On examination of the anterior segment, the cornea was perforated centrally from 3:00 o'clock through 6:00 o'clock to 9:00 o'clock. The perforation continued into the sclera at 3:00 o'clock and 9:00 o'clock. In addition, the upper part of the iris was avulsed from its root and there was complete loss of the lens. Vision at this time was limited to hand movements, IOP was low, the retina was attached and there was vitreous haemorrhage. The necrotic iris tissue was removed the same day with suture of the sclera (7/0 Vicryl), conjunctiva (9/0 Vicryl) and cornea (10/0 Ethilon). The lid was also reconstructed with skin sutures (5/0 Vicryl) nasal and temporal to the left eye; in addition to local cover (gentamicin eyedrops and cefuroxime eyedrops), systemic antibiotics were given for 10 days (cefuroxime $1.5 \mathrm{~g}$ twice daily i.v.). A foreign body was excluded by CT scan. Pars plana vitrectomy of the left eye was performed one week postoperatively to remove the persistent haemophthalmos. This showed subretinal bleeding nasal to the optic disc and temporal to the macula. The lens could not be found in the vitreous space so it can be assumed that it had probably been lost externally in the accident. At operation, the iris was sutured at 12:00 o'clock with 10/0 Prolene. On discharge from hospital, vision on the left was still limited to hand movements, the intraocular pressure was good and the retina was attached.

After further office-based conservative treatment and removal in the interim of loose corneal sutures, vision in the left eye was 0.8 logMAR with aphakia correction $+10.0 \mathrm{dpt}$ eight months after primary wound management of the left eye. The anterior segment was uninflamed and there was aphakia, a large central corneal scar from 3:00 o'clock through 6:00 o'clock to 9:00 o'clock, a deep anterior chamber, an iris defect from 9:00 o'clock through 12:00 o'clock to 3:00 o'clock ( $\bullet$ Fig. 3 ); the intraocular pressure was $20 \mathrm{mmHg}$ and the retina was attached circularly. Because of the reduced vision due to the corneal scar, pronounced glare sensitivity due to the extensive iris defect and aphakia, surgical management of the aphakia and aniridia in combination with keratoplasty of the left eye was planned.

\section{Operation and course}

15 months after the primary management of the left eye, surgical reconstruction was performed using the Ophtec Artificial Iris Model C1 (scleral fixation) shade no. 3223. The refractive strength of the IOL of +24.5 dpt was calculated via IOL-Master 700 (Zeiss) using the SRK-T/II formula with an A constant of 119.4.

Peritomy of the left eye was performed at the start. The ciliary sulcus was marked by diaphanoscopy at 4:00 o'clock, 8:00 o'clock and 12:00 o'clock and corresponding scleral flaps were dissected. A Flieringa ring was placed to stabilise the globe. Cow hitch loops of $10 / 0$ Prolene were then placed in the three loops of the IOL haptic using the Peden technique [4]. The loops were then grasped with hooks. The perforating corneal graft was then

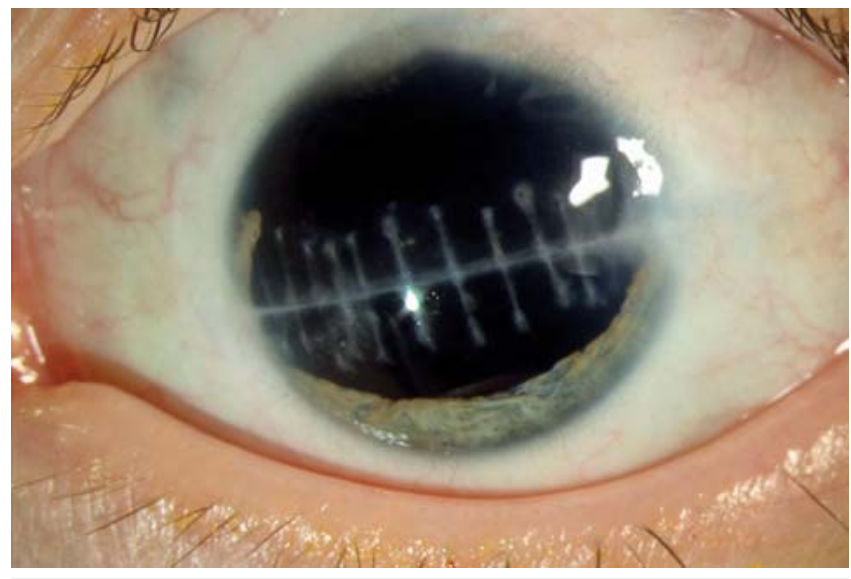

- Fig. 3 Anterior segment on left 8 months after primary management.

performed using the Hessburg-Barron trepanation system $(7.5 \mathrm{~mm})$ on the donor and recipient eye. The previously placed Prolene loops were then threaded through the haptic eyes and the haptics were gripped. This was followed by suture of the corneal graft with four interrupted sutures and a continuous suture using 10/0 Nylon. As the IOL was well centred, it was fixed in the plane of the scleral pocket with the previously placed Prolene sutures. The scleral flaps were closed with 10/0 Nylon. With the IOL correctly in place and the IOP restored the conjunctiva was sutured with 8/0 Vicryl. Postoperative antibiotic cover was provided topically with ofloxacin eyedrops and following epithelial closure, rejection was prevented by dexamethasone eyedrops in addition to systemic rejection prophylaxis with prednisolone in tapering dosage.

3 months postoperatively, vision on the left was $0.7 \operatorname{logMAR}$ and the suture-related astigmatism had already diminished somewhat (subjective refraction in left eye: $\mathrm{sph}+2.0 \mathrm{cyl}-3.0 \mathrm{~A} 100^{\circ}$ ), but a cornea plana-like configuration with central steepening still persisted ( $\bullet$ Fig. 4 a). The left anterior segment continued to be uninflamed, with the transparent graft well in place and the Artificial Iris centred ( $\triangleright$ Fig. 4 b), IOP of $20 \mathrm{mmHg}$ and circularly attached retina. The anterior segment OCT of the left eye showed the iris implant with its lens and prosthetic parts very well, and in the cornea, the junction between the recipient and donor cornea was readily identifiable ( $\boldsymbol{\nabla}$ Fig. $\mathbf{4} \mathbf{c}$ ). The patient was also very happy with the cosmetic outcome (especially compared with the other eye) ( $\triangleright$ Fig. 4 d).

\section{Discussion}

The first surgical methods for reconstructing the iris were developed by Peter Choyce in the 1950s [5]. Since then the range of possible reconstruction variants has widened considerably. Different companies offer models for pure iris reconstruction or alternatively with an additional optic effect.

The Ophtec C1 model used here combines the optic effect of an intraocular lens with reconstruction of the iris. It is a further development of the 311 aniridia IOL II, which had a range of only four 

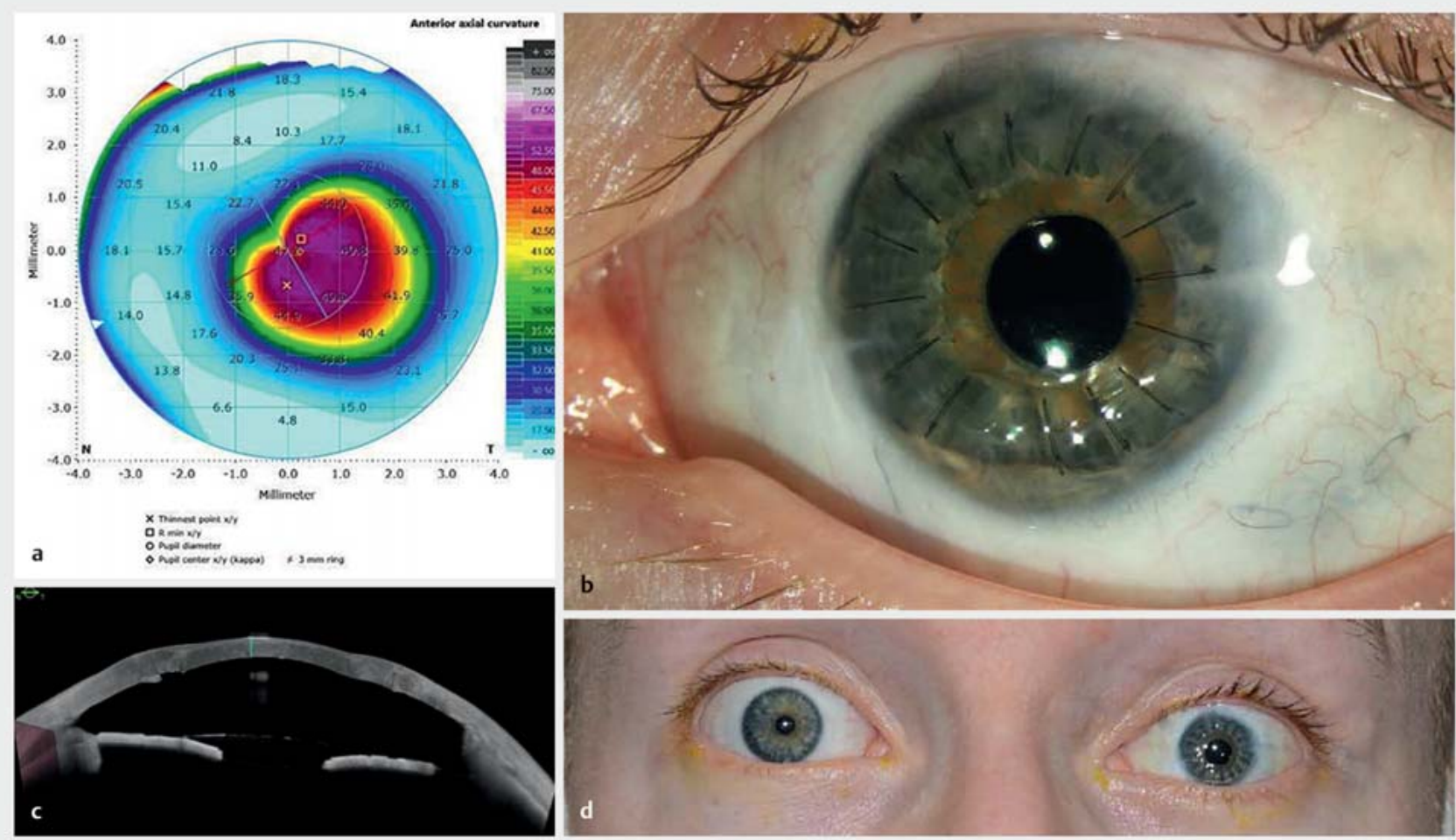

- Fig. 4 From top left to bottom right: a corneal topography on left 3 months postoperatively. b Anterior segment on left 3 months postoperatively. c Anterior segment OCT on left 3 months postoperatively. d Photograph 3 months postoperatively.

different colours (black, green, brown or blue), was suitable for scleral, sulcus and intracapsular fixation and likewise was available with and without a lens [6]. Various studies showed that the postoperative results for this older model were an improvement in vision and reduction in glare sensitivity $[7,8]$. Possible complications included glaucoma, cystoid macular oedema and iritis [8], though such complications were found much more often in eyes that had a complex medical and surgical history [1]. In a case description of implantation of model C1 more than 6 months postoperatively, no complications such as an increase in intraocular pressure or endothelial cell loss were found [9].

Combination of the aniridia IOL with perforating keratoplasty is possible for model 311 and has been described [10]. In an overview of combined IOL implantation, iris reconstruction by a prosthesis (Artificial Iris, Human Optics) and perforating keratoplasty as a triple procedure, the result was an improvement in vision, greater cosmetic satisfaction and overall an improvement in quality of life [11].

In the cases presented here of implantation of the Ophtec aniridia IOL model C1 there was an increase in vision and a marked reduction in glare sensitivity postoperatively in both cases together with a high level of satisfaction with the cosmetic outcome. It was possible to combine this successfully with perforating keratoplasty in one of the presented cases. Up to the present time, none of the possible postoperative complications described in the literature had occurred, such as iritis, increase in intraocular pressure or graft failure [11]. Incipient corneal endothelial decompensation was apparent in case 1 , however, but reference must be made at this point to the patient's age and the previous operations on the affected eye. Based on the still relatively short follow-up period, a final conclusion regarding possible complications cannot yet be drawn.

In summary, based on the two described cases, implantation of the Ophtec aniridia IOL model C1 can be regarded as a practically feasible and low-risk method of iris reconstruction, which produces good postoperative patient satisfaction and can be combined with other surgical procedures (e.g., perforating keratoplasty). The decisive advantages of the model used here are the particularly high stability due to three-point fixation, the possibility of combining a lens and prosthetic iris in one surgical procedure and the high individual matching due to the large choice of shades.

\section{Conflict of Interest}

The authors declare that they have no conflict of interest.

\section{References}

[1] Wang H, Jung J, Lin SR et al. Safety and Efficacy of Colored Iris Reconstruction Lens Implantation. Am J Ophthalmol 2020; 216: 174-185

[2] Koch KR, Heindl LM, Cursiefen C et al. Artificial iris devices: benefits, limitations and management of complications. J Cataract Refract Surg 2014; 40: 376-382 
[3] Szurman P, Gekeler K. Sekundäre Intraokularlinsenimplantation von Sklera-naht-fixierten Intraokularlinsen. Ophthalmologe 2014; 111: 217-223

[4] Peden M, Adams S, Huffman B et al. Alternative technique for implantation of scleral-fixated intraocular lens. J Cataract Refract Surg 2009; 35: 226-229

[5] Choyce P. Intraocular lenses and implants. London, Großbritannien: H. K. Lewis and Company; 1964

[6] Thomas BC, Rabsilber TM, Auffarth GU. Aniridie-IOL und künstlicher Irisersatz. Klin Monbl Augenheilkd 2013; 230: 786-790

[7] Roman S, Cherrate H, Trouvet JP et al. [Artificial iris intraocular lenses in aniridie or iris deficiencies]. J Fr Ophtalmol 2009; 32: 320-325
[8] Menezo JL, Martinez-Costa R, Cisneros A et al. Implantation of iris devices in congenital and traumatic aniridias: surgery solutions and complications. Eur J Ophthalmol 2005; 15: 451-457

[9] Frisina R, De Biasi CS, Londei D et al. A new intraocular lens with artificial iris for treating a case of iris extrusion secondary to traumatic opening of a radial keratotomy. Eur J Ophthalmol 2020. doi:10.1177| 1120672120902035

[10] Mashor RS, Bahar I, Kaisermann I et al. Combined penetrating keratoplasty and implantation of iris prosthesis intraocular lenses after ocular trauma. J Cataract Refract Surg 2011; 37: 582-587

[11] Bonnet C, Vazirnia P, Deng SX et al. Sutured custom foldable Silicone Artificial Iris implantation combined with intraocular lens implantation and penetrating keratoplasty: safety and efficacy outcomes. Cornea 2020. doi:10.1097/ICO.0000000000002564 